\author{
Asian Journal of \\ Medical and Biological Research \\ ISSN 2411-4472 (Print) 2412-5571 (Online) \\ www.ebupress.com/journal/ajmbr
}

\title{
Article \\ Investigation of prevalence and risk factors of subclinical mastitis of dairy buffaloes at Bhola district of Bangladesh
}

\author{
Hasan Aliul ${ }^{1}$, Paul Ashit Kumar ${ }^{1}$, Riad Mohammad Mahmood ${ }^{2}$, Rahman Mizanur ${ }^{1}$ and Ahmed Md. Selim ${ }^{1 *}$ \\ ${ }^{1}$ Department of Medicine, Surgery and Obstetrics, Faculty of Animal Science and Veterinary Medicine, \\ Patuakhali Science and Technology University, Barisal-8210, Bangladesh \\ ${ }^{2}$ Department of Basic Science, Faculty of Animal Science and Veterinary Medicine, Patuakhali Science and \\ Technology University, Barisal-8210, Bangladesh
}

${ }^{*}$ Corresponding author: Md. Selim Ahmed, Department of Medicine, Surgery and Obstetrics, Faculty of Animal Science and Veterinary Medicine, Patuakhali Science and Technology University, Barisal-8210, Bangladesh. Phone +8801718595932; E-mail: selimpstu476@pstu.ac.bd

Received: 14 November 2020/Accepted: 17 December 2020/ Published: 31 December 2020

\begin{abstract}
The subclinical mastitis is more serious and is responsible for much greater loss to the dairy industry in Bangladesh. This study was performed to determine the prevalence of subclinical mastitis and identify the associated risk factors in randomly selected 200 lactating buffaloes (192 local and 8 crossbred) at some selected regions of Bhola district, Bangladesh during the period from March 2018 to February 2019. California Mastitis Test (CMT) was performed on each quarter milk sample of lactating buffaloes at field condition for the determination of subclinical mastitis in dairy buffaloes. Overall prevalence of subclinical mastitis was $10.50 \%$ (21/200). The prevalence of subclinical mastitis (SCM) was comparatively higher in crossbred (12.5\%) as compared to local breed (10.42\%). The highest prevalence of SCM in dairy buffaloes was also found in late lactation period $(12.82 \%)$, age group 7 to 18 years $(13.46 \%)$, rainy season $(11.1 \%)$ and 2nd parity group $(10.74 \%)$. Moreover, the buffaloes graze in free range areas; large and medium sized farms; poor health conditions and other diseases of post parturient period increasing the susceptibility of SCM. For early diagnosis of subclinical mastitis, CMT can be performed regularly as a control measures and emphasis should be provided on farm management practices; particularly on milking hygiene and udder sanitation.
\end{abstract}

Keywords: prevalence; subclinical mastitis; risk factors; dairy buffaloes

\section{Introduction}

Bangladesh is a densely populated agro based developing country where livestock plays a crucial role in the national economy. About $1.54 \%$ of the total Gross Domestic Product (GDP) is contributed by livestock (BBS, 2018). The majority of the dairy cattle belong to small holder dairy producers. Annual milk production in Bangladesh is 9.4 million metric tons and about 95\% milk comes from cattle (DLS, 2017-18). However, Bangladesh has an acute shortage of milk. In present, the produced milk can fulfill only $13.6 \%$ of the total requirement in Bangladesh. Dairying in Bangladesh is growing faster, but it also faces lots of problem including high input cost and low output prices. The diseases along with non-availability of feed resources and nutrition are the most important constraints to milk production. Among the diseases of dairy cows, mastitis is one of the most important infectious diseases. The primary cause of mastitis in cattle, buffaloes, goats and sheep are wellrecognized groups of microorganisms. Among the microbes Streptococcus sp., Staphylococcus sp, Pasteurella sp., and coliforms, Escherichia coli, Enterobacter sp., and Klebsiella sp. are the common mastitis causing pathogen. Yeast and fungus have also been found frequently infecting the udder (Andrews et al., 1985). It has many negative economic impacts on dairy farms in terms of abnormal milk, reduced production, deterioration of milk quality and treatment cost (Seegers et al., 2003). The disease causes huge economic loss to the dairy industry and the annual economic losses due to mastitis have been estimated to be Tk.122.6 (US\$2.11) Million 
(Kader et al., 2002). Early recognition and prompt treatment are important for limiting tissue damage and production losses. However, a large proportion of mastitis, glands are not readily detectable by manual palpation or by visual examination of the milk using a strip cup. In the present state of knowledge, it seems practicable and reasonable to define mastitis as a disease characterized by the presence of significantly increased leucocytes content in the milk from affected gland (Blood et al., 1983). The disease is common in high yielding dairy cows and buffaloes. Infection rate is more in successive lactation than the first lactation. Exotic and cross bred cows and buffaloes are more prone to mastitis. It is well known fact that the sub clinical mastitis (SCM) is more serious and is responsible for much greater loss to the dairy industry in Bangladesh. The prevalence of clinical mastitis in dairy cows of Baghabarighat, Sirajgong has been reported 16\% (Kabir et al., 2017). It has been reported that prevalence of sub clinical mastitis in milch cows 16.52\%with White side test (WST) and $15.77 \%$ with California mastitis test (CMT) from Baghabarighat, Sirajgong district by Prodhan et al., (1996) and 18.5\% with WST from the Mymensingh district by Rahman et al. (1997). Animal breed, farm type, parity of cows, physiological status of animal and milk yield per animal are also found to be important risk factors associated with the occurrence of subclinical mastitis in dairy animals. Khan and Muhammad (2005) reported that overall prevalence of clinical and subclinical mastitis were $5.5 \%$ and $36 \%$ (crossbred cows), $4.0 \%$ and $27 \%$ (buffaloes), respectively. Bilal et al. (1999) also reported 16.72 and $21.08 \%$ clinical mastitis among cattle and buffaloes, respectively. Ali et al. (2011) reported that subclinical mastitis is a great problem in dairy buffaloes in Pakistan which hamper the total milk production of the country. They also found that $44 \%$ of dairy buffaloes are affected with subclinical mastitis in some selected regions of Pakistan. Tripura et al. (2014) revealed the prevalence of subclinical mastitis in lactating cows was 51.8\%, of which 51.4\% at Mymensingh sadar and $52.2 \%$ at Lakshmipur sadar upazilas of Bangladesh. It has been reported that highest prevalence of mastitis in buffaloes as 58\% in backyard management system followed by small holdings in periurban area (42\%) and the lowest at organized farms with reasonable good management conditions (32\%) in Pakistan (Ali et al. 2011). Higher incidence of the disease was observed during winter $(18.8 \%)$ followed by summer $(16.0 \%)$ by Malik and Haq (2009). They also reported that prevalence rate of bovine mastitis in Kashmir valley was 34.0 and 15.4 $\%$ in organized and un-organized farming conditions, respectively. Islam et al., (2011) found higher prevalence of SCM in milch crossbred cows (36.36\%) in comparison to local bred cows (24.61\%) maintained under extensive management system in rural area of Tangail sadar upazila. The prevalence of sub-clinical mastitis in cow was significantly higher in 3rd $(80 \%)$ parity compared to $1^{\text {st }}(38.09 \%)$ and 2 rd $(45.83 \%)$ parity (Sarker and Biswas, 2017). Hygienic milking in cows and buffaloes related to the subclinical mastitis of the individuals. Deng and Asebe (2015) in Ethiopia showed that washing udder was not practiced by $95.17 \%$ of the households, which increases the susceptibility of infection. The literature so far available revealed that no study has been carried out on the prevalence of sub clinical mastitis in dairy buffaloes in Bangladesh. So, present study was performed to know the overall prevalence and associated risk factors of subclinical mastitis in dairy buffaloes at selected study area.

\section{Materials and Methods}

\subsection{Study area and duration}

The study was carried out in different selected areas of Bhola district, Bangladesh. The study was conducted during March 2018 to February 2019.

\subsection{Study design and data collection}

Data were collected from the farmer through questionnaire method. Personal interview of the farmers as well as history of farm will be taken.

\subsection{Sample Size and milk sample collection}

A total of 200 buffaloes were examined throughout the study time to determine the prevalence of sub clinical mastitis. The sample tube $(15 \mathrm{ml})$ were washed with tap water, air dried, plugged and sterilized at $160{ }^{\circ} \mathrm{C}$ in the hot air oven for one hour. The tubes were then labeled indicating the dairy farm, name or number of animal and collection date. Milk samples were collected from buffaloes after washing with clean water along with antiseptic wash of teats with $70 \%$ ethanol and dried of by tissue paper. Two streams of milk were discarded and then $8 \mathrm{ml}$ of milk were taken aseptically into labeled sterilized test tubes with rubber cap at the time of morning milking.

\subsection{Detection of subclinical mastitis}

Immediately after collection of milk, samples were subjected to California mastitis test (CMT). The test procedure are described as below- 


\subsubsection{California Mastitis Test (CMT)}

CMT kit was supplied by ACI Agro vet division, Bangladesh. It is composed of Alkyl Aryl sulfonate (3\%), sodium hydroxide $(1.5 \%)$ and bromocresol purple $(1: 10,000)$ as an indicator. For conducting the CMT, a shallow paddle having four cups was used and rinsed after each use. About $5 \mathrm{ml}$ milk was drawn from bottle into the cup (Figure 1) and an estimated equal volume of CMT reagent was squirted from a polyethylene wash bottle. Mixing was accomplished by gentle circular motion of the paddle in a horizontal plane (Figure 2). The reaction developed almost immediately with milk containing a high concentration of somatic cells (Figure 3). The peak of reaction was obtained within 10 seconds and scored.

\section{Interpretation of CMT test:}

\begin{tabular}{|l|l|}
\hline Severity of infection & Score \\
\hline Severe & +++ \\
\hline Moderate & ++ \\
\hline Mild & + \\
\hline Absent & - \\
\hline
\end{tabular}

\subsection{Statistical analysis}

Prevalence was calculated as the number of positive cases of subclinical mastitis in total collected samples. Data also analyzed by Chi-square test to observe the significant influence of age, parity, stage of lactation, health status, hygienic management, season etc. on subclinical mastitis of buffaloes.

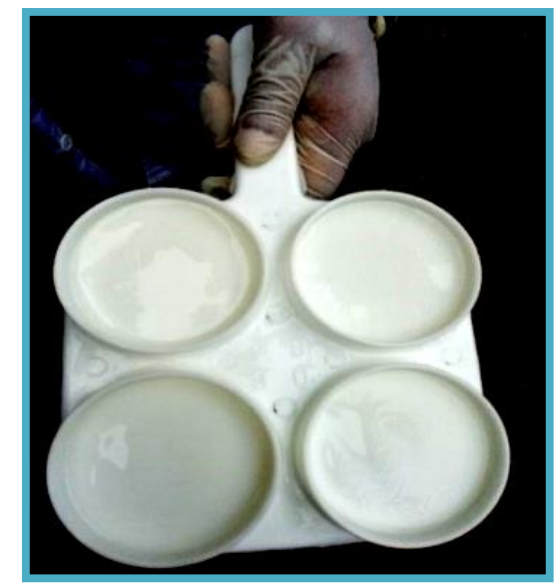

Figure 1. Milk sample from four different teats.

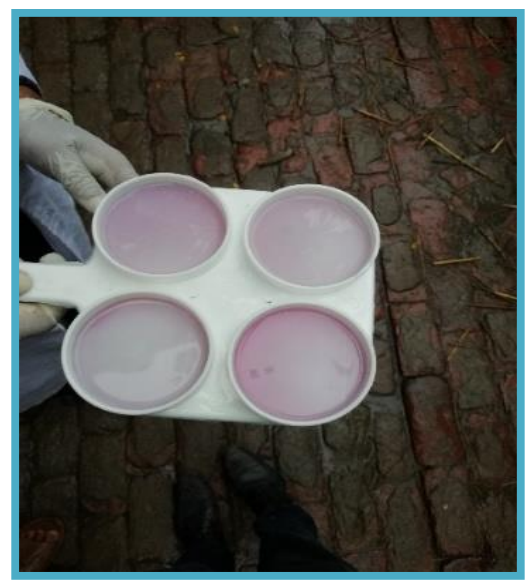

Figure 2. Mixing of reagent and sample.

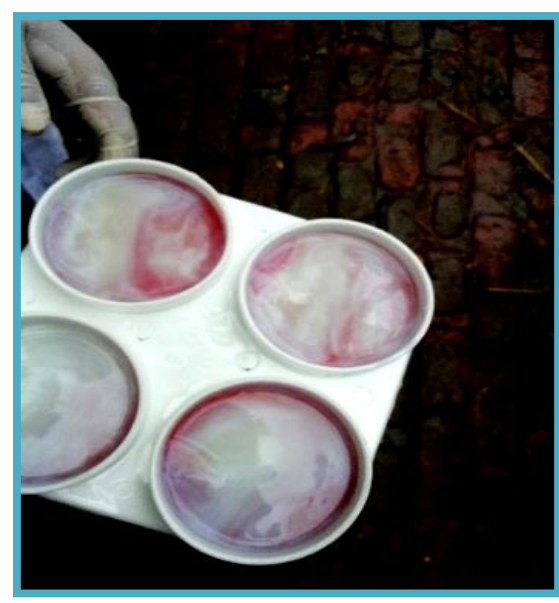

Figure 3. Gel formation of sample in positive cases. 
3. Results

\subsection{Prevalence of subclinical mastitis in buffaloes according to host factor}

The overall prevalence of subclinical mastitis as 21 (10.5\%) from 200 dairy buffaloes. A total of $20(10.42 \%)$ local breed dairy buffalo out of 192 were found to be positive where 1(12.5\%) cross breed out of 8 tested animals gave positive result shown in Table 1 . Among the 21 positive cases from 200 dairy buffaloes, SCM was recorded as 7(7.29\%) and 14(13.46\%) in the age group of 3 to 6 years and 7 to 18 years, respectively shown in Table 1 .The parity wise prevalence of SCM was recorded as $10.13 \%$ and $10.74 \%$ during the parity numbers 1 and 2 , respectively. The present study also showed that the prevalence of subclinical mastitis in dairy buffaloes as $5.88 \%, 10.42 \%$ and $12.82 \%$ in early, mid and late lactation, respectively.

\subsection{Prevalence of subclinical mastitis in buffaloes according to management factor}

The present study showed higher prevalence of subclinical mastitis in dairy buffaloes as $10.99 \%$ which were reared in free range grazing area as compared with stall feeding area as $5.56 \%$. The present study also showed that comparatively higher prevalence of subclinical mastitis in dairy buffaloes as $11.51 \%$ which are affected with post parturient diseases as compared with none affected as $8.20 \%$, respectively. The present study revealed the prevalence of subclinical mastitis in dairy buffaloes as $11.02 \%, 10.29 \%$ and $0 \%$ in poor, medium and good health conditions, respectively. It has also been found that highest prevalence of subclinical mastitis in medium medium sized farms of dairy buffaloes as $11.76 \%$ followed by large $(9.71 \%)$ and small $(8.33 \%)$ sized farm shown in Table 2.

\subsection{Season wise prevalence of subclinical mastitis in buffaloes}

Among the 21 positive cases from 200 dairy buffaloes, 7(10.94\%) was recorded in summer, 10(10\%) in winter and $4(11.11 \%)$ in rainy season, respectively shown in Table 3.

Table 1. Prevalence of subclinical mastitis in buffaloes according to host factor.

\begin{tabular}{|c|c|c|c|c|c|}
\hline Variable & Category & No. of observation & $\begin{array}{l}\text { Subclinical mastitis (+) ve } \\
\mathbf{N}(\%)\end{array}$ & $\begin{array}{l}\text { Chi square } \\
\text { value }\end{array}$ & $P$ value \\
\hline \multirow[t]{2}{*}{ Breed } & Local & 192 & $20(10.42 \%)$ & \multirow{2}{*}{0.035} & 0.851 \\
\hline & Cross & 8 & $1(12.5 \%)$ & & NS \\
\hline \multirow[t]{2}{*}{ Age } & Age 3-6 years & 96 & $7(7.29 \%)$ & \multirow{2}{*}{0.022} & 0.155 \\
\hline & $7-18$ years & 104 & $14(13.46 \%)$ & & NS \\
\hline \multirow[t]{2}{*}{ Parity } & Parity $1(1-3)$ & 79 & $8(10.13 \%)$ & \multirow{2}{*}{0.019} & 0.889 \\
\hline & Parity 2 (4-next) & 121 & $13(10.74 \%)$ & & \\
\hline \multirow{3}{*}{$\begin{array}{l}\text { Lactation } \\
\text { period }\end{array}$} & Early (15-90 days) & 17 & $1(5.88 \%)$ & \multirow{3}{*}{0.610} & \multirow{3}{*}{$\begin{array}{l}0.737 \\
\text { NS }\end{array}$} \\
\hline & Mid (90-180 days) & 144 & $15(10.42 \%)$ & & \\
\hline & Late $(>180$ days $)$ & 39 & $5(12.82 \%)$ & & \\
\hline & Total & 200 & $21(10.5 \%)$ & & \\
\hline
\end{tabular}

NS: Non significant at 5\% level of probability

Table 2. Prevalence of subclinical mastitis in buffaloes according to management factor.

\begin{tabular}{|c|c|c|c|c|c|}
\hline Variable & Category & No. of observation & $\begin{array}{l}\text { Subclinical mastitis } \\
\text { (+) ve } N(\%)\end{array}$ & $\begin{array}{l}\text { Chi square } \\
\text { value }\end{array}$ & $P$ value \\
\hline \multirow[t]{2}{*}{ Feeding management } & Free range area & 182 & $20(10.99 \%)$ & \multirow{2}{*}{1.116} & 0.572 \\
\hline & Stall feeding area & 18 & $1(5.56 \%)$ & & NS \\
\hline \multirow{2}{*}{$\begin{array}{l}\text { History of post } \\
\text { parturient diseases }\end{array}$} & Present & 139 & $16(11.51 \%)$ & \multirow{2}{*}{0.495} & 0.481 \\
\hline & Absent & 61 & $5(8.20 \%)$ & & NS \\
\hline \multirow[t]{3}{*}{ Health status } & Poor & 127 & $14(11.02 \%)$ & \multirow{3}{*}{0.627} & \multirow{3}{*}{$\begin{array}{l}0.731 \\
\text { NS }\end{array}$} \\
\hline & Medium & 68 & $7(10.29 \%)$ & & \\
\hline & Good & 5 & $0(0 \%)$ & & \\
\hline \multirow[t]{3}{*}{ Farm size } & Large $(>50)$ & 103 & $10(9.71 \%)$ & \multirow{3}{*}{0.627} & \multirow{3}{*}{$\begin{array}{l}0.731 \\
\text { NS }\end{array}$} \\
\hline & Medium (11-50) & 85 & $10(11.76 \%)$ & & \\
\hline & Small (1-10) & 12 & $1(8.33 \%)$ & & \\
\hline
\end{tabular}

NS: Non significant at 5\% level of probability 
Table 3. Prevalence of subclinical mastitis according to the season.

\begin{tabular}{|l|l|l|l|l|}
\hline Level & No. of observation & Mastitis (+) veN (\%) & Chi square value & P value \\
\cline { 1 - 2 } Summer & 64 & $7(10.94 \%)$ & & \multirow{2}{*}{0.973} \\
Winter & 100 & $10(10 \%)$ & & NS \\
\cline { 1 - 2 } Rainy & 36 & $4(11.11 \%)$ & & \\
\hline
\end{tabular}

NS: Non significant at $5 \%$ level of significant

\section{Discussion}

\subsection{Prevalence of subclinical mastitis in dairy buffaloes according to host factor}

Among 200 dairy buffaloes, 21 buffalos were found positive with subclinical mastitis in study area. The overall prevalence of subclinical mastitis was recorded as $10.5 \%$ (Table 1). Ali et al. (2011) reported overall prevalence $44 \%$ in dairy buffaloes at Punjab, Pakistan, which is higher than the reported data. Kader et al. (2002) also reported higher prevalence of SCM in dairy cows 46.6\%. Recently, Meher et al., (2018) reported overall prevalence of SCM in dairy cows as $28.50 \%$. The variation of prevalence rates of subclinical mastitis in dairy cows might be due to different breeds of animals, management practices, geographical location and the tests used for screening of the milk samples.

In performed study, among 192 local breed 20(10.42\%) buffaloes were found to be positive with SCM tests and among 8 Murrah breed 1(12.5\%) animals gave positive result shown in Table 1. The present study indicates that prevalence of SCM was comparatively higher in cross bred than local individuals. Islam et al. (2011) also found higher prevalence in cross bred than local bred cows in their study, which support the present data. It has been reported that high yielding cows are more prone to udder infection than low producing one (Hossain, 2004 and Radostits et al., 2000). Srinivashan et al. (2013) also found the same results in their study.

In present study, among the 21 positive cases from 200 dairy buffaloes SCM was recorded as 7(7.29\%) and $14(13.46 \%)$ in the age group of 3 to 6 years and 7 to 18 years, respectively (Table 1). Islam et al. (2011) reported comparatively higher prevalence of subclinical mastitis in dairy cows as $27.94 \%$ in the age group 5 to 7 years than age group 8 to 10 years as $18.19 \%$ which is disagree with the present data. The dairy cows of $8-10$ years age group are yielding low milk production and less susceptible to SCM as compare to other age group. But, Rahman et al. (2010) support the present data. The increase in subclinical mastitis with age is consistent with other studies (Kader et al. 2003, Ghosh et al. 2004 and Radostits et al. 2000).

According to Table 1, the prevalence of SCM in dairy buffaloes was recorded as $10.13 \%$ and $10.74 \%$ during the parity numbers 1 and 2, respectively. Srinivashan et al. (2013) showed the prevalence of SCM in cows was recorded in $17.94 \%, 20.58 \%, 23.07 \%$ and $32.50 \%$ during the parity numbers $1,2,3$ and 4 respectively which is quite similar to the current study. It has been reported that the prevalence of SCM in cows were recorded as $18.75 \%, 22.22 \%, 29.55 \%$ and $26.66 \%$ during the parity numbers 1, 2, 3 and 4, respectively (Rahman et al. 1997). Gebriwahid et al. (2012) reported $18.33 \%, 34.78 \%, 32.13 \%$ and $14.55 \%$ prevalence of SCM in $1^{\text {st }}, 2^{\text {nd }}$, $3^{\text {rd }}$ and $4^{\text {th }}$ parity, respectively in dairy cows which is dissimilar with present study. The high parity cows have less defense status as their teat sphincter get loosen and cellular defense lowered; resulting the organism to get easy entrance through the teat canal on the contrary younger cows are less susceptible to mastitis because of their more effective defense mechanism. Polymorphoneuclear leukocytes functions well in primiparous cows than multiparous ones (Roy et al., 1998). This result also is in agreement with the observation made by Kapur and Singh,( 1975) who reported comparatively higher incidence rate of mastitis in $2^{\text {nd }}$ parity than $1^{\text {st }}$ one. The finding of present study also support with the findings of Rasool et al., (1985). They also reported that cows had an increase trend of mastitis, as the parity increase.

The present study showed that the prevalence of subclinical mastitis in dairy buffaloes as $5.88 \%, 10.42 \%$ and $12.82 \%$ in early, mid and late lactation, respectively (Table 1). Deng and Asebe (2015) reported 56.52\%, $64.71 \%$ and $57.45 \%$ in early, mid and late lactation, respectively which is slightly similar to the present study. Srinivashan et al. (2013) also reported similar observation as reported by Gebriwahid et al. (2012).

\subsection{Prevalence of subclinical mastitis in dairy buffaloes according to management factor}

The present study showed higher prevalence of subclinical mastitis in dairy buffaloes as $10.99 \%$ which were reared in free range grazing area (non organized farm) as compared with stall feeding area (organized farm) as $5.56 \%$, respectively shown in Table 2 . The present study inclined with the study of Ali et al. (2011) where they showed that low prevalence of SCM of dairy buffaloes in organized farm with reasonable good managemental conditions $(32 \%)$ and high prevalence in non organized peri urban area as $42 \%$. 
The present study showed higher prevalence of subclinical mastitis in dairy buffaloes as $11.51 \%$ which were affected of post parturient diseases as compared with none affected individuals as $8.20 \%$, respectively shown in Table 2. The result is supported with Rahman et al., (2010) where they also showed that other post parturient diseases of cows increase the susceptibility of subclinical mastitis in dairy cows. The lower immunity level of periparturient cows makes the cow more prone to infection in the udder by Rainard and Riollet, (2006). Calcium ions are necessary for muscle constriction. For this reason, low level of calcium decreases the rigidity of the teat sphincter that might be allows the organism to pass into the udder (Paape and Guidry, 1993). In addition, the cows which were infected with metritis causing release of uterine discharge and retained placenta increase the risk of udder and teats being contaminated (Peeler et al., 1994).

The present study showed that the prevalence of subclinical mastitis in dairy buffaloes as $11.02 \%, 10.29 \%$ and $0 \%$ in poor, medium and good respectively (Table 2).Usually good health condition of animals is naturally more immunocompetent than poor health individuals. It has been reported that high yielding dairy cows have high non specific udder resistance than low milk yielding cows.

The present study showed higher prevalence of subclinical mastitis in medium sized farms of dairy buffaloes (11.76\%) than large $(9.71 \%)$ and small sized farm (8.33\%) shown in Table 2. Ali et al. (2011) reported highest prevalence of SCM in individual holding buffalo farms (52\%) followed by small holdings (48\%) and organized farms (32\%) of dairy buffaloes at Punjab, Pakistan, which is dissimilar to present study due to the different regions, therapeutic management of diseased buffaloes, hygienic management of farm and presence of microorganisms in environment. Nooruddin et al., (1997) and Rahman et al., (1997) also reported that percentage of mastitis is higher in large and medium sized farm and support the present study.

\subsection{Season wise prevalence of subclinical mastitis in dairy buffaloes}

Among the 21 positive cases from 200 dairy buffaloes, 7(10.94\%) was recorded in summer, 10(10.0\%) in winter and $4(11.11 \%)$ in rainy season, respectively shown in Table 3 . The occurrence of mastitis varies from season to season, because growth and multiplication of organisms depends on specific temperature and humidity. Incorrect ventilation, with high temperature and relative humidity, encourages the multiplication of various bacteria. Exposure of animals to high temperature can increase the stress of the animal and alter immune functions by Sudhan and Sharma (2010). The dairy cows were more prone to SCM in the monsoon season compared with summer or winter by Joshi and Gokale (2006) which is similar to present study. Dego and Tareke (2003) also showed that prevalence rate is comparatively higher in the rainy season than dry season. Most of the owner of dairy buffaloes in study area avoid dry season as parturition time due to deficiency of grazing land and stress factor which might be involved with reduce the prevalence rate of mastitis in dry season.

\section{Conclusions}

Mastitis is a common problem of dairy industries. The overall prevalence of subclinical mastitis in dairy buffaloes at some selected regions of Bhola district in Bangladesh was $10.50 \%$. The prevalence of subclinical mastitis (SCM) was comparatively higher in crossbred as compared to local breed. The highest prevalence of SCM in dairy buffaloes was also found in late lactation period, age group 7 to 18 years, rainy season and 2nd parity group of dairy buffaloes. Moreover, the buffaloes graze in free range areas; large and medium sized farms; poor health conditions and other diseases of post parturient period increasing the susceptibility of SCM. Udder hygiene and proper milking management methods, proper installation, function and maintenance of milking equipment, dry cow management and therapy, appropriate therapy of mastitis during lactation, culling chronically infected cows, good record keeping, periodic review of the udder health management will help to take the challenges of mastitis control program. A well-documented continued research and educational effort is required to increase awareness to the farmers or relevant personnel of dairy enterprise. Further study should be performed to determine the specific causal agents, antimicrobials and genetic analysis of the agents to curb the mastitis in mentioned study area.

\section{Acknowledgements}

The study was performed as part of thesis work of Master of Science (MS in Medicine) under the department of Medicine, Surgery and Obstetrics, Faculty of animal Science and Veterinary Medicine of Patuakhali Science and Technology University, Bangladesh. The authors would like to express profound gratitude to the staffs and owner of the Bathan and to the Upazila Livestock Office of Lalmohon and Bhola Sadar of Bhloa district, Bangladesh. 
Conflict of interest

None to declare.

\section{References}

Ali MA, MD Ahmad, M Kamrul and AA Anjum, 2011. Prevalence of Subclinical Mastitis in Dairy Buffaloes of Punjab, Pakistan. J. Anim. Plant Sci., 21: 477-480.

Andrews ML, TA Mollett, RT Marshall and HD Keisler, 1985. Incidence of subclinical mastitis in ewe and impact on lamb performance, Missouri Sheep Report, University of Missouri and Lincoln University. Nov/85.

Bangladesh Bureau of Statisitics (BBS), 2018. Statistical Yearbook of Bagladesh-2018. Dhaka, Bangladesh.

Bilal MQ, A Shafia and M Latif, 1999. Incidence of Mastitis in Cows at Various Stages of Lactation in Urban and Rural Areas of Faisalabad District. J. Anim. Plant Sci., 9: 13-14.

Blood DC, Radostits RO, Henderson JA, Arundel JH, Gay CC, 1983. Veterinary Medicine- A Textbook of the Diseases of Cattle, Sheep, Pigs, Goats and Horse, 6th ed. BailliereTindall, London, pp. 1310.

Dego OK and F Tareke, 2003. Bovine mastitis in selected areas of southern Ethiopia. Trop. Anim. Health Prod., 35: 197-205.

Deng Y and G Asebe, 2015. Assessment of Hygienic Milk Production and Prevalence of Mastitis in Dairy Cow in JikawoWoreda of Nuer Zone, Gambella Region, Ethiopia. J. Agric. Nat. Resour. Sci., 2: 480-486.

Department of Livestock Services (DLS), 2017-18. Livestock Economy at Glance 2017-18. MoFL, Bangladesh.

Gebriwahid TT, BH Abera and HT Menghistu, 2012. Prevelence and etiology of subclinical mastitis in small ruminants of Tigray Regional state, North Etiopia. Vet. World, 5: 103-109.

Ghosh CP, PK Nagpaul and S Prasad, 2004. Factor affecting subclinical mastitis in Sahiwal cows. Indian Journal of Dairy Science, 57: 127-130.

Hossain SMA, 2004. Efficacy of dry cow therapy in mastitis control strategy, MS Thesis, Department of Surgery and Obstetrics, Faculty of Veterinary Science, Bangladesh Agricultural University, Mymensingh, Bangladesh.

Islam MA, MZ Islam, MS Rahman and MT Islam, 2011. Prevalence of Subclinical Mastitis in Dairy Cows in Selected Areas of Bangladesh. Bangl. J. Vet. Med., 9: 73-78.

Joshi S and S Gokhali, 2006. Status of Mastitis as an Emerging Disease and Improve and Periurban Dairy Farms in India. Annals of the New York Academy of Sciences, 1081: 74-83.

Kabir HM, Ershaduzzaman, Giasuddin, I Rafiqul and KHM Hussain, 2017. Prevalence and identification of subclinical mastitis in cows at BLRI Regional Station, Sirajganj, Bangladesh, Adv. Vet. Anim. Res., 4: $295-$ 300.

Kader MA, MA Samad and S Saha, 2003. Influence of host level factors on prevalence and economics of subclinical mastitis in dairy cows in Bangladesh. Indian Journal of Dairy Science, 56 : 235-240.

Kader MA, MA Samad, S Saha and MA Taleb, 2002. Prevalence and Etiology of Sub-clinical Mastitis with Antibiotic Sensitivity to Isolated Organisms among Milch Cows in Bangladesh. Indian Journal of Dairy Science, 55: 218-223.

Kapur MP and RP Singh, 1975. Mastitis in dairy animals, etiology, chemotherapeutic sensitivity and drug traits. Haryana State Indian Veterinary Journal, 14: 107-110.

Khan AZ and G Muhammad, 2005. Quarter- wise Comparative Prevalence of Mastitis in Buffaloes and Crossbred Cows. Pak. Vet. J., 25: 9-12.

Malik HU and ZU Haq, 2009. Prevalence of bovine mastitis under different husbandry conditions of Kashmir. Appl. Biol. Res., 11: 36-39.

Meher MM, A Hasan and M Afrin, 2018. Field Investigation on Sub-clinical Mastitis in Cows in Different areas of Barisal district in Bangladesh. Turkish Journal of Agriculture - Food Science and Technology, 6: 11591162.

Nooruddin M, MS Rahman and MM Rahman, 1997. Occurrence distribution of mastitis in crossbred and exotic dairy cows. Bangladesh Veterinary Journal, 14: 14-44.

Paape MJ and A Guidry, 1993. The teat defenses of mammary gland. Adv. Exp. Med. Biol., 225: 457-463.

Peeler EJ, MJ Otte and RJ Esslemont, 1994. Interrelationship of periparturient diseases in dairy cows. The Veterinary Record, 5: 129-132.

Prodhan MAM, AHM Kamal and ATM Mahbub-E-Elahi, 1996. Prevalence of subclinical mastitis in cows of Baghabari Milkshed area. Bangladesh Veterinary Journal, 30: 59-61.

Radostits OR, DC Blood, CC Gay and KW Hinchcliff, 2000. Mastitis. In; Vesterinary Medicine, A text book of the diseases of cattle, sheep, goats and horses. $8^{\text {th }}$ ed. BaillerTindall, London. pp. 603-700. 
Rahman MM, MR Islam, MB Uddin and M Aktaruzzaman, 2010. Prevalence of subclinical mastitis in dairy cows reared in Sylhet District of Bangladesh. International Journal of Bioresearch, 1: 23-28.

Rahman MS, M Nooruddin and MM Rahman, 1997. Prevalence and Distribution of Mastitis in Crossbred and Exotic Dairy Cows. Bangladesh Veterinary Journal, 14: 1-4.

Rainard P and C Riollet, 2006. Innate immunity of the bovine mammary gland. Vet. Res., 37: 369-400.

Rasool G, MA Jabber, SE Kazi and A Ahmed, 1985. Incidence of subclinical mastitis in Nili-Ravi buffaloes and Sahiwal cows. Pak. Vet. J., 5: 76-78.

Roy A. MM Rahman, A Rahman and MR Ali, 1998. Occurrence of Staphylococci and Streptococci organisms on the udder skin and on the milk samples of apparently healthy cattle. Bangladesh Veterinary Journal, 3: 2123.

Sarker T and D Biswas, 2017. Prevalence of Subclinical Mastitis at Banaripara Upazilla, Barisal. Bangl. J. Vet. Med., 15: 21-26.

Seegers H, C Fourichon and F Beaudeau, 2003. Production effects related to mastitis and mastitis economics in dairy cattle hards. Vet. Res., 34: 475-491.

Srinivashan PD, R Jagadeswaran, Manoharan, T Giri, GA Balasubramaniam and P Balachandran, 2013. Prevalnce and etiology of subclinical mastitis among buffaloes (Bubalusbubalus) in Namakkal, India. Pak. J. Biol. Sci., 16: 1776-1780.

Sudhan NA and N Sharma, 2010. Mastitis-an important production disease of dairy animals. SMVS' Dairy Year Book.

Tripura TK, SC Sarker, SK Roy and P Mirmiran, 2014. Prevalence of Subclinical Mastitis in Lactating Cows and Efficacy of Intramammary Infusion Therapy. Bangl. J. Vet. Med., 12: 56-62. 